\title{
Effects of Diamond Nanoparticles on the Microstructure, Hardness and Corrosion Resistance of Chromium Coatings
}

\author{
Vladimir Petkov*, Radoslav Valov \\ Institute of Metal Science, Equipment and Technologies, Bulgarian Academy of Sciences, Sofia, Bulgaria \\ Email address: \\ vladimir2pe@yahoo.com (V. Petkov), radoslav.valov@gmail.com (R. Valov) \\ ${ }^{*}$ Corresponding author
}

\section{To cite this article:}

Vladimir Petkov, Radoslav Valov. Effects of Diamond Nanoparticles on the Microstructure, Hardness and Corrosion Resistance of Chromium Coatings. American Journal of Chemical Engineering. Vol. 8, No. 6, 2020, pp. 125-130. doi: 10.11648/j.ajche.20200806.11

Received: October 20, 2020; Accepted: November 4, 2020; Published: November 27, 2020

\begin{abstract}
Electrodeposited coatings of chromium and diamond nanoparticles on steel were obtained. The chromium is plated directly on the steel matrix without any intermediate layers. The influence of the electrodeposition current density, the electrodeposition time and the concentration of diamond nanoparticles in the chromium-plating electrolyte on the microstructure, the phase composition, the microhardness and the corrosion resistance of the chromium coatings were investigated. The phase and chemical compositions of the composite coating (chromium and diamond nanoparticles) were examined using X-ray Diffraction (XRD) and Scanning Electron Microscopy - Energy-Dispersive X-ray Spectroscopy (SEM-EDS) techniques. The microstructure and microhardness were examined with a metallographic microscope and a microhardness tester. The corrosion resistance was investigated in $3.5 \mathrm{wt} \% \mathrm{NaCl}$ solution using the gravimetric method. The bond between the chromium coating and the steel matrix has diffusion character. A sublayer of separate irregular shape formations appears at concentration of diamond nanoparticles $25 \mathrm{~g} / 1$ and more. The formation of these structures depends only on the concentration of diamond nanoparticles and is not influenced by the other electrodeposition parameters. With the increase of the concentration of diamond nanoparticles in the electrolyte the rate of chromium coating deposition increases and respectively the thickness of the coating increases also. This increase is more than twice the thickness of chromium coating without nanodiamonds. The microhardness of the composite coatings rises also compared to unmodified chromium coating. With the increase of the concentration of the diamond nanoparticles 2 times greater microhardness is achieved and up to 5 times greater corrosion resistance compared to monochromium coating. The values of the other electroplating parameters are constant.
\end{abstract}

Keywords: Diamond Nanoparticles, Chromium Coating, Electrodeposition, Hardness, Corrosion

\section{Introduction}

Alloying steels with $\mathrm{Cr}$, Ni and other transition metals like Mo, Ti, W and $\mathrm{V}$ improves their chemical and mechanical properties such as hardness and corrosion resistance in aggressive environment. However, the production of alloyed steels is associated with a number of technological difficulties - high temperature $\left(1600^{\circ} \mathrm{C}-1700^{\circ} \mathrm{C}\right)$, special furnaces, etc. To find cheaper alternatives coatings are applied. Some coatings obtained by sol-gel technology provide enhanced corrosion resistance [1]. But they are very thin less than $1 \mu \mathrm{m}$, and cannot be applied on items exposed to abrasion and wear conditions. Surface treatment of plain, unalloyed steels with hard and corrosion resistant metals is economically advantageous and has a high technological effect. One technique used for this purpose is electrochemical metal plating, electrochemical chromium plating included. Still more important for the properties of the surface is the application of composite coating of chromium and diamond nanoparticles (ND) on unalloyed low and medium carbon steel. The properties and yield of diamond nanoparticles produced by detonation synthesis differ with the different methods - wet and dry [2]. The wet synthesis is much more effective. Chromium plating with diamond nanoparticles at different electrochemical conditions was studied [3]. The data published in the scientific literature on modified with nanodiamonds chromium-plated coatings and their properties are incomplete and controversial [4-9]. It has been found that 
they have increased microhardness and increased resistance to corrosion in hostile environment compared to non-modified chromium coating. Surface morphology and chemical composition of coatings are studied by V. P. Isakov et al [4]. According to V. Y. Dolmatov et al the wear resistance of composite coatings is $13 \%$ higher [5]. On the other hand K. L. Tikhonov et al, using different diamond stock, achieve 1.4 to 1.8 times higher wear resistance [8]. There are numerous studies on the subject of various types of substrate materials coated with nanoparticles-modified coatings. Chromium coating with ND plated on sintered steel items improves considerably their hardness, wear and corrosion resistance [10]. The influence of ND on the structure and tribological properties of chromium composite coatings is investigated [11]. The mechanical and chemical properties of the coatings are improved. The deposition of nickel coatings with $\mathrm{TiO}_{2}$ nanoparticles on aluminum alloys increases their hardness and corrosion resistance [12]. Modified with diamond nanoparticles chromium coating applied on aluminum alloys enhances the mechanical and chemical properties of their surface $[13,14]$.

The objective of the present research is to obtain composite coatings of chromium and ND with increased chemical and mechanical properties on unalloyed medium carbon steel and to investigate the impact of the electrochemical parameters and the concentration of diamond nanoparticles $\left(\mathrm{C}_{\mathrm{ND}}\right)$ in the chromium plating electrolyte on the characteristics and the properties of the composite coating.

\section{Experimental}

Test samples of cylindrical shape with a height of $60 \mathrm{~mm}$ and a diameter of $6 \mathrm{~mm}$, made of medium-carbon steel $\mathrm{C} 45$, were used. The samples were pre-degreased with dichloroethane and ethanol, dried and pickled in 20 vol. \% aqueous solution of $\mathrm{H}_{2} \mathrm{SO}_{4}$ at temperature of $50^{\circ} \mathrm{C}$ for 5 to 10 minutes, then washed thoroughly with water and dried. The ready samples were weighed on an analytical balance with an accuracy of $\pm 1.10^{-4} \mathrm{~g}$. Electrochemical chromatization was carried out using an electrolyte with a composition of $220 \mathrm{~g} / 1$ $\mathrm{CrO}_{3}$ and $2.2 \mathrm{~g} / 1 \mathrm{H}_{2} \mathrm{SO}_{4}$. The value of the deposition current density varied from 40 to $80 \mathrm{~A} / \mathrm{dm}^{2}$ and that of the deposition time from 15 to $45 \mathrm{~min}$. The temperature of the electrolyte was in the interval $50^{\circ} \mathrm{C}-55^{\circ} \mathrm{C}$. The anode was made of lead. $\mathrm{ND}$ with dimensions ranging from $4 \mathrm{~nm}$ to $20 \mathrm{~nm}$ were added to the electrolyte in the form of an aqueous suspension. The ND were obtained by detonation synthesis. They were derived from graphite and carbon-rich organic compounds in special chambers, without heating, under high pressure and then thoroughly cleaned [15]. The electrolyte with added ND was activated before galvanization in an ultrasonic bath. The value of the concentration of diamond nanoparticles $\left(\mathrm{C}_{\mathrm{ND}}\right)$ in the electrolyte varied from 10 to $40 \mathrm{~g} / \mathrm{l}$. During galvanization, the electrolyte suspension was stirred with a magnetic stirrer at $150 \mathrm{rpm}$ to disperse the ND and to prevent their sedimentation. The following characteristics of the chromium-plated samples were defined by gravimetric (change of weight) and metallographic analyzes: chromium yield (the quantity of chromium deposited on the cathode) and the layer's thickness, microstructure and microhardness. The phase and chemical compositions of the composite coating (chromium with diamond nanoparticles) were examined by X-ray Diffraction (XRD) analysis with Siemens D500 diffractometer and Bragg-Brentano (B-B) technique and Scanning Electron Microscopy Energy-Dispersive X-ray Spectroscopy (SEM-EDS) techniques. The microstructure and microhardness were examined on metallographic specimens with a Polywar-Met metallographic microscope and a Micro-Duromat 4000 microhardness tester at a load $50 \mathrm{~g}$, loading time $10 \mathrm{~s}$ and holding time at the maximum load $10 \mathrm{~s}$. The changes of the coating properties were investigated as a function of current density, duration of the process and $\mathrm{C}_{\mathrm{ND}}$. The distribution of chromium along the layer thickness and its phase composition were studied using Energy Dispersive Spectrometry (EDS) and X-ray diffraction analysis (XRD), respectively. The corrosion resistance was investigated in 3.5 wt $\%$ aqueous solution of $\mathrm{NaCl}$ using the gravimetric method.

\section{Results and Discussion}

Figure 1 shows the relation of chromium yield on current density and $\mathrm{C}_{\mathrm{ND}}$ at constant value of time. As can be seen from the figure, the chromium yield increases with the rise of the current density and $\mathrm{C}_{\mathrm{ND}}$. The optimum value of the yield is reached for values of the current density in the range from 40 to $80 \mathrm{~A} / \mathrm{dm}^{2}$, which was the range for our study.

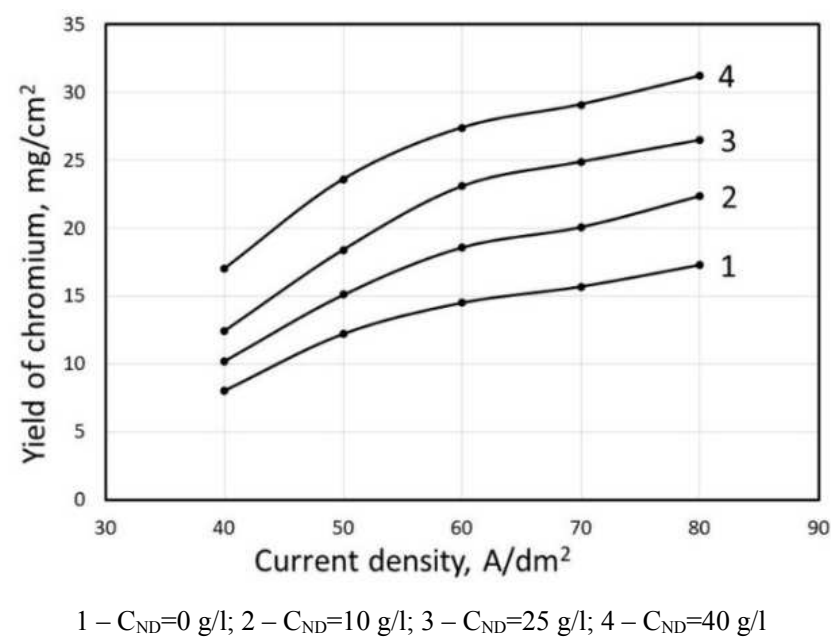

Figure 1. The relation of chromium yield (on the cathode) on $C_{N D}$ and current density at constant value of time - $45 \mathrm{~min}$.

The chromium yield was determined by gravimetric method as the difference in the weights of the samples prior to and after galvanization per unit surface area. Its relation on time at different values of $\mathrm{C}_{\mathrm{ND}}$ for constant current density $40 \mathrm{~A} / \mathrm{dm}^{2}$ is presented in Figure 2. 


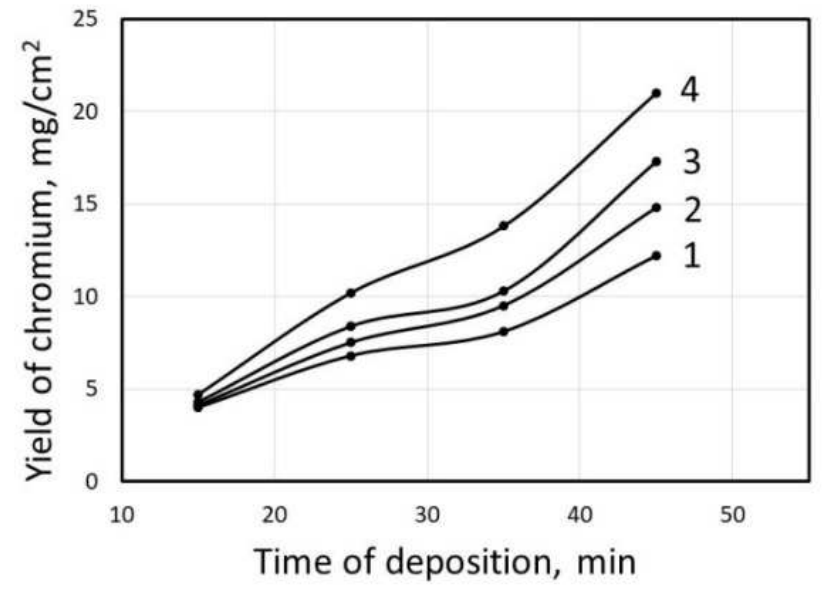

$1-\mathrm{C}_{\mathrm{ND}}=0 \mathrm{~g} / \mathrm{l} ; 2-\mathrm{C}_{\mathrm{ND}}=10 \mathrm{~g} / 1 ; 3-\mathrm{C}_{\mathrm{ND}}=25 \mathrm{~g} / \mathrm{l} ; 4-\mathrm{C}_{\mathrm{ND}}=40 \mathrm{~g} / 1$

Figure 2. The relation of chromium yield (on the cathode) on $C_{N D}$ and time of deposition at constant current density $40 \mathrm{~A} / \mathrm{dm}^{2}$.

It can be seen from the figure that the chromium yield rises with the increase of deposition time at constant $\mathrm{C}_{\mathrm{ND}}$ and also with the increase of $\mathrm{C}_{\mathrm{ND}}$ at constant values of temperature and current density. The thickness, microstructure and microhardness of the plated layer were determined using metallographic analysis. Metallographic specimens were cut out from the plated test pieces, polished and pickled to reveal their structure. The microstructures were examined with a Polywar metallographic microscope. The thickness of the plated layer was measured using Olympus microimage quantitative analysis system. Figure 3 shows the microstructures of electrodeposited layers of nanodiamond-modified chromium coatings obtained from electrolytes with varying $\mathrm{C}_{\mathrm{ND}}$ at constant values of current density and deposition time. Figure $3 \mathrm{a}$ shows the microstructure of a monochromium coated sample $\left(\mathrm{C}_{\mathrm{ND}}=0\right.$ $\mathrm{g} / \mathrm{l})$. Figures $3 \mathrm{~b}, 3 \mathrm{c}$ and $3 \mathrm{~d}$ show the microstructures of composite coatings electrodeposited using electrolytes with $\mathrm{C}_{\mathrm{ND}}$ values of 10,25 and $40 \mathrm{~g} / 1$, respectively.
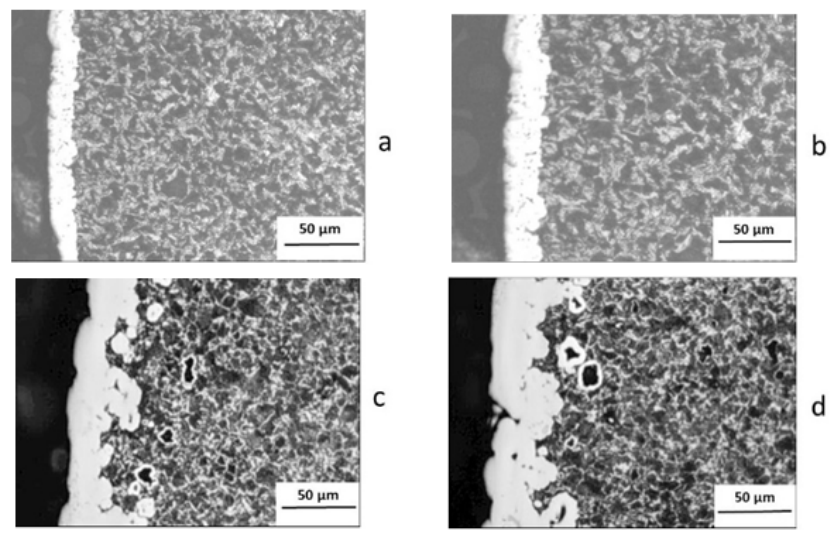

a) $\mathrm{C}_{\mathrm{ND}}=0 \mathrm{~g} / \mathrm{l}$; b) $\mathrm{C}_{\mathrm{ND}}=10 \mathrm{~g} / \mathrm{l}$; c) $\mathrm{C}_{\mathrm{ND}}=25 \mathrm{~g} / \mathrm{l}$; d) $\mathrm{C}_{\mathrm{ND}}=40 \mathrm{~g} / \mathrm{l}$;

Figure 3. Microstructures of composite chromium coatings obtained by electrodeposition from electrolytes with varying values of $C_{N D}$ at current density $40 \mathrm{~A} / \mathrm{dm}^{2}$ and time of deposition $45 \mathrm{~min}$.

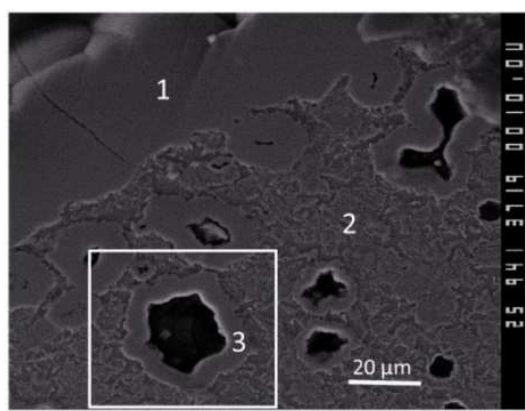

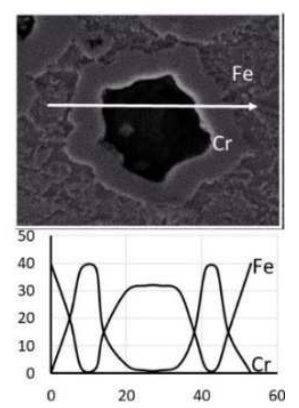

b
Figure 4. Composite chromium coating, electrodeposited from an electrolyte with $C_{N D}=25 \mathrm{~g} / \mathrm{l}$ at current density $40 \mathrm{~A} / \mathrm{dm}^{2}$ and time of deposition $45 \mathrm{~min}$.

a) SEM image: 1 - chromium coating with ND; 2 - steel matrix; 3 minisection

b) Intensity of $\mathrm{K} \alpha$ lines of $\mathrm{Fe}$ and $\mathrm{Cr}$ across the "minisection" structure.

The "minisections" are partially or fully covered with a bright shell of varying thickness and only the fully covered "minisections" are part of the main composite coating (Figure $4 a)$. Figure $4 \mathrm{~b}$ shows the change in the intensity of the $\mathrm{K} \alpha$ lines of $\mathrm{Fe}$ and $\mathrm{Cr}$ at various points in and around a "minisection" studied with X-ray microanalyser. As can be seen that in the matrix area (the steel) the intensity of the $\mathrm{K} \alpha$ line of $\mathrm{Fe}$ is high, while that of $\mathrm{Cr}$ is zero. At the point, positioned at the boundary of the matrix area with the bright shell, the intensity of the $\mathrm{K} \alpha$ line of Fe decreases, while that of $\mathrm{Cr}$ increases. At the shell the intensity of the $\mathrm{K} \alpha$ line of $\mathrm{Cr}$ is the highest, and that of Fe is zero. That is to show that the bright shell of the "minisections" consists of chromium only. Another evidence is that the microhardness of the "minisection" shell, which is $9125 \mathrm{MPa}$, is comparable with that of the main composite coating - $9613 \mathrm{MPa}$ (Figure 4a).

Figure 5 shows the change of the microhardness of the composite coatings, electroplated at the same values of the electroplating parameters, as a function of $\mathrm{C}_{\mathrm{ND}}$. The microhardness of the steel matrix at the area just beneath the coating is also shown.

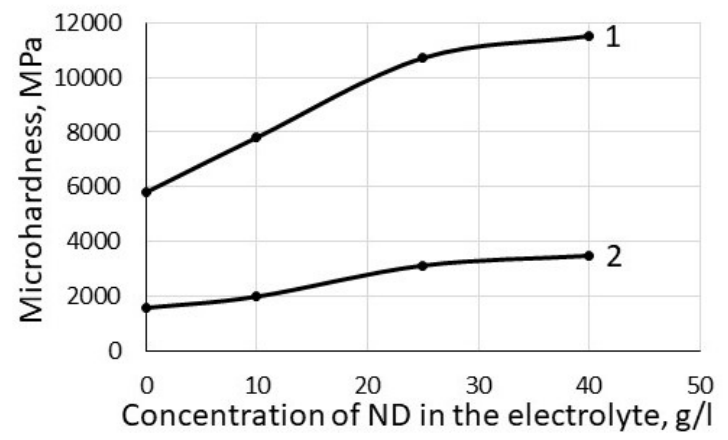

1 - chromium coating; 2 - steel matrix

Figure 5. Change of the microhardness $H$ of composite chromium coatings as a function of $C_{N D}$ at current density $40 \mathrm{~A} / \mathrm{dm}^{2}$ and time of deposition $45 \mathrm{~min}$.

It can be seen that the microhardness of the composite coatings increases with the rise of $\mathrm{C}_{\mathrm{ND}}$. At $\mathrm{C}_{\mathrm{ND}}=40 \mathrm{~g} / \mathrm{l}$, the microhardness is $11600 \mathrm{MPa}$, which is twice that of the 
unmodified chromium coating. The microhardness of the steel matrix at the area just beneath the coating also increases approximately two times compared to chromium coating only. It is obvious that the formation of a sublayer containing the "minisections" at increased $\mathrm{C}_{\mathrm{ND}}$ values is due to the presence of ND in the chromium-plating electrolyte. ND obtained by detonation synthesis (such as those used in this study) have surface electronic configuration with a predominance of $\mathrm{sp}^{2}$ electrons [15]. After being obtained, they are cleaned thoroughly by subjecting them to a series of techniques including treatment with oxidizing acids, heating in air and in Ar atmosphere, hardening, washing and deagglomeration. In the course of these, on the surface of the particles ions and entire functional groups have been adsorbed, which move with them. Part of the $\mathrm{sp}^{2}$ electrons form $\mathrm{sp}^{3}$ hybridized electron configuration, which is the normal electron configuration of the carbon atom [16]. The authors assume that the diamond nanoparticles, present in the electrolyte, adsorb chromate and other ions - $\mathrm{CrO}_{4}{ }^{2-}$, $\mathrm{Cr}_{2} \mathrm{O}_{7}{ }^{2-}, \mathrm{Cr}^{3+}, \mathrm{Cr}^{2+}, \mathrm{H}^{+}, \mathrm{SO}_{4}{ }^{2-}$. Between ions with different chemical composition and electrode potential, which are adsorbed on the surface of the ND, occur processes of electron exchange and oxireduction. As result of these processes neutral atoms of chromium are obtained that form the "minisections". This line of reasoning allows for the presence of diamond nanoparticles in the coating structure. Studies of the phase and elemental composition of the layer were performed with X-ray Diffraction (XRD) and Scanning Electron Microscopy - Energy Dispersive X-ray Spectroscopy (SEM-EDS) techniques. The results obtained are presented in Figures 6 and 7.

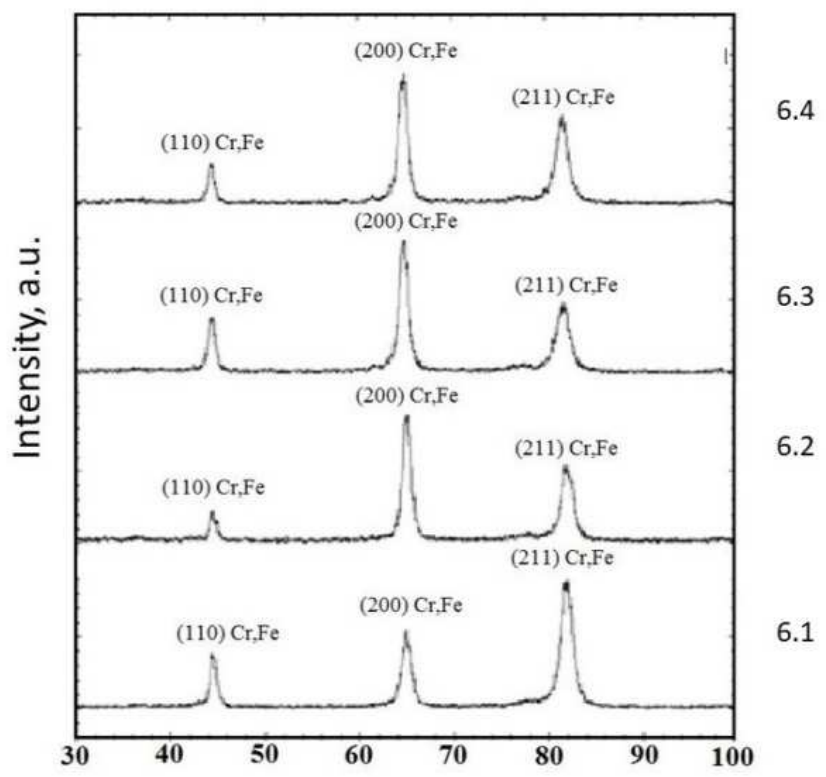

Figure 6. Diffraction patterns of chromium coatings electrodeposited at deposition time $45 \mathrm{~min}$.

6.1 and 6.2 are obtained from chromium-plating electrolyte with $\mathrm{C}_{\mathrm{ND}}=0$ at current density $40 \mathrm{~A} / \mathrm{dm}^{2}$ and $60 \mathrm{~A} / \mathrm{dm}^{2}$ respectively;

6.3 and 6.4 are obtained from chromium-plating electrolyte with $\mathrm{C}_{\mathrm{ND}}=10 \mathrm{~g} / \mathrm{l}$ at current density $40 \mathrm{~A} / \mathrm{dm}^{2}$ and $60 \mathrm{~A} / \mathrm{dm}^{2}$ respectively
Figure 6 shows the diffraction patterns of chromium coatings on steel obtained from chromium-plating electrolyte free of diamond nanoparticles (6.1 and 6.2) and with $\mathrm{C}_{\mathrm{ND}}=10 \mathrm{~g} / \mathrm{l}$ (6.3 and 6.4). The values of the current density and deposition time are the same for both types of coatings: 40 and $60 \mathrm{~A} / \mathrm{dm}^{2}$ and $45 \mathrm{~min}$ respectively. The $\mathrm{X}$-ray diffraction patterns in Figure 6 were taken with Bragg-Brentano (B-B) technique. They identify the presence of chromium in the layer. No diffraction effect of ND in the layer was found. The X-ray diffraction analysis established that the well-defined peaks at $2 \theta=44^{\circ}, 2 \theta=64^{\circ}$ and $2 \theta=82^{\circ}$ corresponding to diffraction planes (110), (200) and (211) are the same for the unmodified chromium coatings (6.1 and 6.2) and the composite coatings (6.3 and 6.4). The surface morphology and the distribution of elements $\mathrm{Cr}, \mathrm{Fe}$ and $\mathrm{C}$ along the layer thickness were investigated with SEM-EDS techniques. The results obtained are presented in Figure 7.
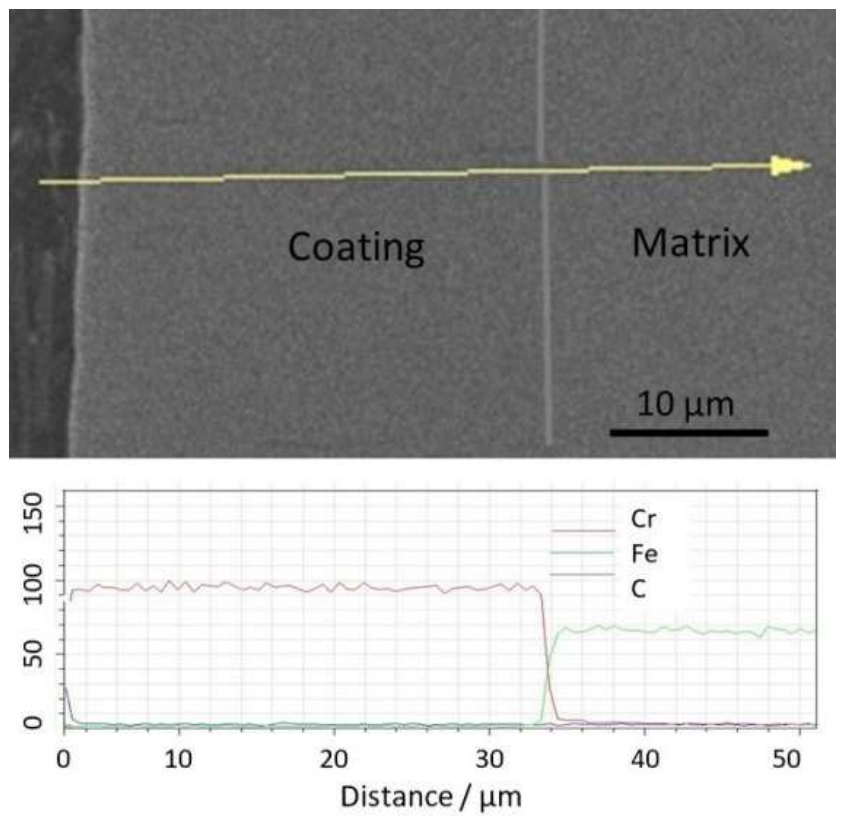

Figure 7. Distribution of elements of a chromium coating electrodeposited from electrolyte with $C_{N D}=40 \mathrm{~g} / \mathrm{l}$

Figure 7 presents the microstructure of metallographic sample cut from the coating. The electrolytic process is performed from electrolyte with $\mathrm{C}_{\mathrm{ND}}=40 \mathrm{~g} / \mathrm{l}$ at current density $60 \mathrm{~A} / \mathrm{dm}^{2}$ and deposition time $45 \mathrm{~min}$. The concentrations of $\mathrm{Cr}, \mathrm{Fe}$ and $\mathrm{C}$, expressed in mass \%, are along the line in the coating. It can be seen that the chromium content is high and constant along the entire coating. The chromium content decreases in the area adjacent to the matrix and that of $\mathrm{Fe}$ increases. The two curves - of the decreasing $\mathrm{Cr}$ content and of the increasing Fe content intersect. In the area outlining the boundary between the coating and the matrix, the change of the chromium and the iron content is not sharp which shows the diffusion character of the bond between the two metals. The carbon content in the coating is zero, rising in the transition zone and in the steel. There is no evidence of ND participation in the chromium coating. 
The corrosion resistance of chromium coatings was studied in 3.5 wt. \% aqueous solution of $\mathrm{NaCl}$ and temperature of $35^{\circ} \mathrm{C}$ using the gravimetric method. The duration of stay in the salt solution was $88 \mathrm{~h}$ and $200 \mathrm{~h}$. The corrosion resistance was determined by the mass loss (the difference in weight before and after the corrosion test). It is calculated per unit area of the sample $\left(\mathrm{mg} / \mathrm{cm}^{2}\right)$. Figure 8 shows the results obtained according to the mass loss method. The chromium coatings were prepared at the same values of the electroplating parameters: current density $40 \mathrm{~A} / \mathrm{dm}^{2}$, duration of the electrolytic process $45 \mathrm{~min}$ and the temperature of the electrolyte was $55^{\circ} \mathrm{C}$. The values of $\mathrm{C}_{\mathrm{ND}}$ were $0,10,25$ and 40 $\mathrm{g} / 1$.

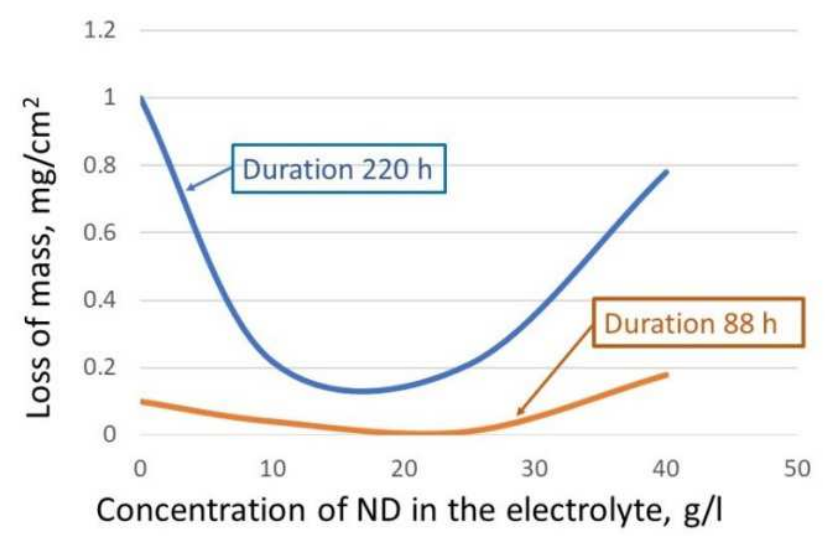

Figure 8. Corrosion resistance as a function of $C_{N D}$ of the chromium coatings in $3.5 \mathrm{wt} \%$ aqueous solution of $\mathrm{NaCl}$.

Corrosion resistance decreases with the rise of the duration time in the corrosion solution. The corrosion of the chromium coatings obtained from electrolytes with $\mathrm{C}_{\mathrm{ND}}$ above $10 \mathrm{~g} / \mathrm{l}$ at duration time in the corroding solution of $88 \mathrm{~h}$ is practically zero with little increase at $\mathrm{C}_{\mathrm{ND}} 40 \mathrm{~g} / \mathrm{l}$. The corrosion resistance of the coatings obtained from electrolytes with $\mathrm{C}_{\mathrm{ND}}$ varying from 10 to $25 \mathrm{~g} / \mathrm{l}$ at duration in the corrosion solution of $200 \mathrm{~h}$ is 4-5 times greater than that of the unmodified chromium coating.

\section{Conclusions}

1) Electrochemically plated chromium coatings modified with diamond nanoparticles, deposited on unalloyed medium-carbon steel 45 , were obtained.

2) The chromium coating is deposited directly on the steel matrix without any intermediate layers.

3) The chromium yield (the amount of metal deposited on the cathode) and respectively the thickness of the chromium coating with ND increases with the rise of the electroplating current density, the galvanizing time and the concentration of diamond nanoparticles in the electrolyte at constant composition and temperature of the electrochemical bath.

4) The mechanical and chemical properties of chromium coating with ND increase with the rise of the concentration of diamond nanoparticles in the electrolyte
$\mathrm{C}_{\mathrm{ND}}$, the values of the other galvanizing parameters remaining constant. For $\mathrm{C}_{\mathrm{ND}}=40 \mathrm{~g} / \mathrm{l}$, the microhardness of the composite coating is 2 times higher than that of unmodified chromium coating. The corrosion resistance in a $3.5 \mathrm{wt} . \% \mathrm{NaCl}$ solution for duration in the corrosion solution for 200 hours is 4 to 5 times greater for chromium coating obtained from electrolyte with $\mathrm{C}_{\mathrm{ND}}$ in the interval from 10 to $25 \mathrm{~g} / \mathrm{l}$ as compared to unmodified chromium coating.

5) Above a certain concentration threshold the diamond nanoparticles influence the mechanism of composite coatings building. With a concentration of ND in the electrolyte above $25 \mathrm{~g} / 1$ a sublayer is formed which participates in the structure formation of the coating in a way not known by now.

6) The effect of modifying the chromium coatings on steel with diamond nanoparticles is significant and reveals new possibilities for surface processing technology of metals and alloys.

\section{References}

[1] Yordanov S., Stambolova I., Lakov L., Blaskov V., Jivov B., Alexandrova M., Valkanov S., Eliyas A., Sol-gel $\mathrm{SiO}_{2}$ coatings doped with $\mathrm{Nd}_{2} \mathrm{O}_{3}$, Bulgarian Chemical Communications, Special Issue A, vol. 49, (2017), 29-32.

[2] Shenderova O., Dieter M., Nanocrystalline Diamonds, Willian Andrew Publishing, Norwich, N.Y., USA, (2006), 335-342.

[3] Dolmatov V., Burkat G., Myllymäki V. and Vehanen A., Electrochemical chromium-diamond coating, Journal of Superhard Materials, vol. 37, (2015), 82-100.

[4] Isakov V. P., Lyamkin A. I., Nikitin D. N., Salimova A. S. and Solntcev A. V., Structure and properties of chromium composite electrochemical coatings, Physical Chemistry of Surfaces and Protection of Materials (Fizikohimia Poverchnosti i Zaschtita Materialov), vol.46, No 5, (2010), 506- 509 .

[5] Dolmatov V. Y., Fujimura T., Barkat G. K. and Veretennikova M. V., Preparation of wear-resistant chromium coatings using different types on nanodiamonds, Powder Metallurgy and Metal Ceramics, vol. 42, No 11-12, (2003), 587-591.

[6] Mandlich N. V. and Dennis J. K., Codeposition of nanodiamonds with chromium, Metal Finishing, June, (2001), $117-121$.

[7] Vityas P. A., Zhornik V. I., Shtemplyak R. G. and Kovaleva S. A., Influence of nanosized carbon additives on the structure, formation and tribological behavior of galvanic chrome coatings, Friction and Wear (Trenie i Iznos), vol. 30, No 2, (2009), 132-139.

[8] Tikhonov K. L., Barkat G. K., Dolmatov V. Y. and Orlova E. A., Use of diamond stock in chromium plating, Russian Journal of Applied Chemistry, vol. 80, No 7, (2007), 1082- 1086.

[9] Barkat G. K., Dolmatov V. Y, Osawa E. and Orlova E. A., A study of properties of chromium diamonds coatings using nanodiamonds from various producers, Super Hard Materials (Sverkhtverdye Materialy), vol. 32, No 2, (2010), 43-59. 
[10] Petkov V., Valov R., Witkowska M., Madej M., Cempura G., Sułowski M., Sintered steels coated with a chromium layer doped with diamond nanoparticles, Arch. Metall. Mater. vol.64, No 4, (2019), 1633-1638.

[11] Nguyen V. H., Hoang T. N., NguyenN. T., Kwon S. C., Joo M. $\mathrm{K}$. and Lee Y., Cr/nanodiamonds composite plating with cobalt cation additive, Metals Society of China, 19, (2009), 975-978.

[12] Wang L., Gao Y., Xue Q., Liu H. and Xu T., Effects of nano-diamond particles on the structure and tribological property of Ni-matrix nanocomposite coatings, Materials Science and Engineering, A 390 (2005), 313- 318.

[13] Addel A., Hard and corrosion resistant nanocomposite coating for Al alloy, Materials Science and Engineering, A, 474 (2008), 181-187.

[14] Gidikova N., Sulowski M., Madej M., Valov R., Petkov V., Mechanical properties of composite coatings of chromium and nanodiamonds on aluminum, MATEC Web of Conferences, $145,05012,(2018), 1-2$.

[15] Krueger A., The structure and reactivity of nanoscale diamonds, Journal of Materials Chemistry, 18, (2008), 1485-1492.

[16] Raty J. Y., Galli G., Bosted C., van Bauren T. W. and Terminello L. Y., Quantum confinement and fullerene like surface reconstruction in nanodiamonds, Phys.Rev.Lett., 90. 037401, (2003). 